\begin{tabular}{|c|l|}
\hline Title & High-yield synthesis of PVP-stabilized small Pt clusters by microfluidic method \\
\hline Author(s) & Hossain, M. Jakir; Tsunoyama, Hironori; Y amauchi, Mino; Ichikuni, Nobuy uki; Tsukuda, Tatsuya \\
\hline Citation & $\begin{array}{l}\text { Catalysis Today, 183(1), 101-107 } \\
\text { https://doi.org/10.1016j.cattod.2011.10.008 }\end{array}$ \\
\hline Issue Date & 2012-03-20 \\
\hline Doc URL & http://hdl.handle.net/2115/49006 \\
\hline Type & article (author version) \\
\hline File Information & CT1831_101-107.pdf \\
\hline
\end{tabular}

Instructions for use 


\title{
High-yield synthesis of PVP-stabilized small Pt clusters by microfluidic method
}

\author{
M. Jakir Hossain, ${ }^{\dagger}$ Hironori Tsunoyama, ${ }^{\dagger}$ Miho Yamauchi, ${ }^{\dagger}$ Nobuyuki Ichikuni, ${ }^{\ddagger}$ and \\ Tatsuya Tsukuda ${ }^{*}+$
}

${ }^{\dagger}$ Catalysis Research Center, Hokkaido University, Nishi10, Kita21, Sapporo 001-0021, Japan, tDepartment of Applied Chemistry and Biotechnology, Graduate School of Engineering, Chiba University, Inage-Ku, Chiba 263-8522, Japan

Email: tsukuda@cat.hokudai.ac.jp

Telephone: +81-11-706-9155; Fax: +81-11-706-9156

\begin{abstract}
Monodisperse PVP-stabilized Pt nanoparticles (PtNPs) with an average diameter of $1.4 \pm$ $0.3 \mathrm{~nm}$ were efficiently produced via the complete reduction of $\mathrm{Pt}^{4+}$ ions by $\mathrm{BH}_{4}^{-}$in a micromixer. Because of microfluidic mixing, hydrolytic decomposition of $\mathrm{BH}_{4}{ }^{-}$by the PtNPs formed in the initial stage of the reaction was suppressed, and hence, the PtNP yield was higher than that in the conventional batch mixing. The results of various spectroscopic analyses including EXAFS, FTIR of CO and XPS revealed that the microfluidically synthesized PtNPs were negatively charged and had a high population of edges and vertices on their surface. The PtNPs dispersed in oxygen-saturated water catalyzed the selective oxidation of $\mathrm{PhCH}_{2} \mathrm{OH}$ to $\mathrm{PhCHO}$.
\end{abstract}

\section{Highlights:}

- Microfluidic method enhanced the yield of PtNPs.

- The PVP-stabilized PtNPs were small and monodisperse $(1.4 \pm 0.3 \mathrm{~nm})$.

- The PVP-stabilized PtNPs were negatively charged.

- The PVP-stabilized PtNPs in water oxidized $\mathrm{PhCH}_{2} \mathrm{OH}$ selectively to $\mathrm{PhCHO}$.

Keywords: PVP-stabilized Pt nanoparticles, micromixer, aerobic alcohol oxidation, reusable catalyst. 


\section{Introduction}

Finely dispersed particles of transition metals have long been used as catalysts for various chemical transformations by taking advantage of intrinsic chemical properties of these metals and the large surface areas of the metal particles. Recently, much attention has been paid on their catalytic application from the viewpoint of reduction of environmental impact and conservation of precious resource [1]. One of the most extensively studied reactions is the aerobic oxidation of alcohols in water in the presence of Pt nanoparticles (PtNPs) as catalysts [2-6]. Since the ubiquitous oxygen is used as the oxidant instead of stoichiometric amounts of heavy-metal oxidants such as $\mathrm{CrO}_{3}$ and $\mathrm{KMnO}_{4}$, production of harmful byproducts are suppressed in the reaction $[7,8]$. Efficient production of small monodisperse PtNPs is desirable for the following reasons: (1) the amount of Pt, a precious metal, can be minimized by increasing the surface-to-volume ratio of the NPs; (2) the catalytic activity per unit surface area increases with a decrease in NP size as suggested by Liu [6].

In general, PtNPs are prepared via the chemical reduction of $\mathrm{Pt}^{4+}$ ions by hydrogen $[6,9]$, alcohols [2, 5, 10-13], borohydride [14-18], glycol [3, 6], or ethylene glycol [19, 20] in the presence of a stabilizer or on a solid support (Scheme 1). Among the aforementioned reducing agents, borohydride $\left(\mathrm{BH}_{4}^{-}\right)$is most suitable for minimizing the particle size because it enables rapid reduction to afford very small nuclei, whose growth is hindered. However, the PtNP yield is very low when using $\mathrm{BH}_{4}{ }^{-}$because of the incomplete reduction of the precursor ions $[14,17,18]$. According to Crooks, this incomplete reduction is due to the formation of a $\mathrm{Pt}^{2+}$ intermediate, which does not undergo further reduction to $\mathrm{Pt}^{0}$ [17]. Somorjai proposed that the reduction of $\mathrm{Pt}^{2+}$ by $\mathrm{BH}_{4}^{-}$is hindered by the multidentate coordination of $\mathrm{Pt}^{2+}$ with the amide groups of the poly(amidoamine) dendrimer [18]. In contrast, Glaunsinger pointed out a possibility that the incomplete reduction of $\mathrm{Pt}^{4+}$ ions is due to the efficient hydrolysis of $\mathrm{BH}_{4}{ }^{-}$by the PtNPs formed in the initial stages of the reaction (Scheme 1) [14]. This rapid hydrolysis of $\mathrm{BH}_{4}{ }^{-}$has frequently been made use of to produce $\mathrm{H}_{2}$ for hydrogenation reactions [21]. Hence, fresh $\mathrm{BH}_{4}^{-}$should be supplied continuously to reduce $\mathrm{Pt}^{4+}$ ions using a fluidic system, so that the PtNPs-catalyzed 
hydrolysis of $\mathrm{BH}_{4}^{-}$is prevented and the PtNP yield is increased via the efficient reduction of the $\mathrm{Pt}^{4+}$ ions. In addition, microfluidic system will provide monodisperse PtNPs because of homogeneous mixing of the solutions of $\mathrm{Pt}^{4+}$ and $\mathrm{BH}_{4}^{-}$, as demonstrated in the production of Au clusters (1.1 nm) [22]. In this article, we report the high-yield synthesis of poly(N-vinyl-2-pyrrolidone) (PVP)-stabilized small monodisperse PtNPs (Pt:PVP; diameter: $1.4 \pm 0.3 \mathrm{~nm}$ ) using a micromixer. The results of spectroscopic characterization showed the unique electronic and geometric features of Pt:PVP; the PtNPs were negatively charged and had a high population of low-coordination sites on their surface. The microfluidically synthesized Pt:PVP catalyzed the aerobic oxidation of $\mathrm{PhCH}_{2} \mathrm{OH}$ to selectively afford $\mathrm{PhCHO}$ as opposed to previously reported PtNPs, which afforded $\mathrm{PhCO}_{2} \mathrm{H}[2,3,5,6]$.

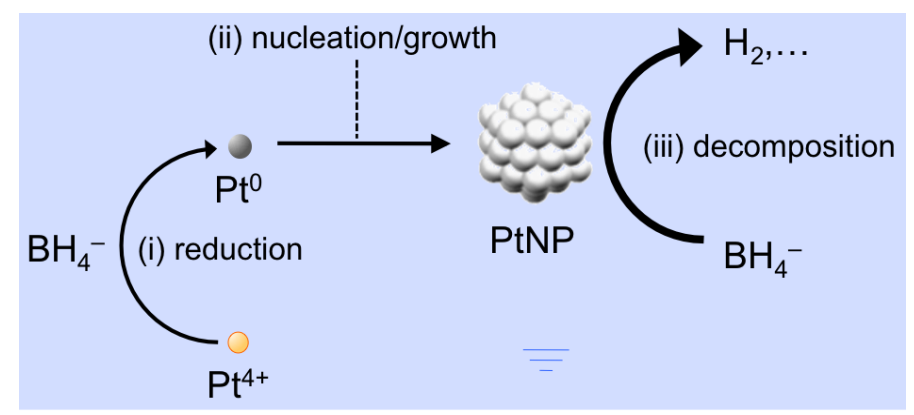

Scheme 1. Schematic representation of PtNP production by batch mixing of $\mathrm{Pt}^{4+}$ and $\mathrm{BH}_{4}^{-}$. Step (i): reduction of $\mathrm{Pt}^{4+}$ to $\mathrm{Pt}^{0}$ by $\mathrm{BH}_{4}{ }^{-}$; step (ii): nucleation and growth of the resulting $\mathrm{Pt}^{0}$ to form PtNPs; step (iii): rapid decomposition of $\mathrm{BH}_{4}{ }^{-}$by the PtNPs, causing most of the $\mathrm{Pt}^{4+}$ ions to remain unreduced. In a fluidic system, the yield of the PtNPs is greatly enhanced because fresh $\mathrm{BH}_{4}{ }^{-}$is supplied continuously to reduce $\mathrm{Pt}^{4+}$.

\section{Experimental}

\subsection{Chemicals and materials}

Hexachloroplatinic acid hexahydrate $\left(\mathrm{H}_{2} \mathrm{PtCl}_{6} \cdot 6 \mathrm{H}_{2} \mathrm{O}\right.$, Tanaka Kikinzoku Kougyo), PVP (average molecular weight: 40,000; TCI, Tokyo Kasei), sodium borohydride $\left(\mathrm{NaBH}_{4}\right.$, Wako Pure Chemical Industries Ltd.), ethylene glycol (Wako Pure Chemical Industries Ltd.), ethanol (Junsei Chemical Co. Ltd.), and CO gas (99.5\% purity) were of the analytical grade and were used as purchased without 
further purification. Deionized water $(18 \mathrm{M} \Omega \mathrm{cm})$ was used to prepare aqueous solutions.

\subsection{Preparation of Pt:PVP}

\subsubsection{Microfluidic reduction with $\mathrm{BH}_{4}^{-}$(sample a)}

Pt:PVP particles with the smallest possible diameters were prepared by mixing the following two solutions in a micromixer (interdigital triangular mixer, mgt mikroglas technik AG, Germany). Solution 1 was prepared by dissolving PVP $(311 \mathrm{mg})$ in a chilled $\left(\sim 5{ }^{\circ} \mathrm{C}\right)$ aqueous solution of $\mathrm{H}_{2} \mathrm{PtCl}_{6}$ (4.0 mM, $35 \mathrm{~mL}$ ) such that the molar ratio between the PVP monomer units and Pt is 20:1. Solution 2 was prepared by dissolving $\mathrm{NaBH}_{4}(26.5 \mathrm{mg})$ in a chilled $\left(\sim 5^{\circ} \mathrm{C}\right)$ aqueous solution $(35 \mathrm{~mL})$ of PVP (311 mg). Then, solutions 1 and $\mathbf{2}$ were loaded into two syringes and injected by automatically actuated syringe pumps into the micromixer placed in an ice bath. Both the syringe pumps were activated simultaneously with a constant flow rate of $200 \mathrm{~mL} / \mathrm{h}$. The feed streams were split into 15 substreams (height: $\sim 150 \mu \mathrm{m}$, width: $\sim 50 \mu \mathrm{m}$ ) and brought together in the mixing chamber. This multilamination enhances the contact area of the two solutions and leads to efficient mixing by rapid diffusion. The hydrosol containing Pt:PVP eluted through the outlet and was collected in a conical flask equipped with a magnetic stirrer. The PVP-monomer-to-Pt molar ratio was 40:1. The initial and final few drops of the elution were discarded in order to prevent contamination of the elute by the fractions with inhomogeneous mixing.

The Pt:PVP hydrosol was diluted with deionized water so that the total volume became $120 \mathrm{~mL}$. This diluted hydrosol was passed through a membrane filter having a cut-off molecular weight of 10 kDa (VIVA FLOW 50, Sartorius Stedim Biotech) with a help of a pump (MASTERFLEX model 71800) at a flow rate of $8 \mathrm{~mL} / \mathrm{min}$. Optical spectroscopy analysis of the filtrate confirmed that there was no leakage of the PtNPs. After the volume of the Pt:PVP hydrosol was reduced to approximately $4 \mathrm{~mL}$ by the filtration, $25 \mathrm{~mL}$ of deionized water was added, and the filtration step was repeated. The dilution and filtration steps were repeated 6-10 times for the complete removal of inorganic ions. The purified Pt:PVP (sample a) was freeze-dried, pulverized using a pestle, and stored in a desiccator. 


\subsection{Batch reduction with $\mathrm{BH}_{4}^{-}$(sample $\left.\mathbf{a}^{\prime}\right)$}

Pt:PVP was also prepared by batch mixing of the aqueous solutions of $\mathrm{H}_{2} \mathrm{PtCl}_{6}$ and $\mathrm{NaBH}_{4}$ in order to study the effect of the mixing method. Using a micropipette, a chilled $\left(\sim 5^{\circ} \mathrm{C}\right)$ aqueous solution of $\mathrm{NaBH}_{4}(0.1 \mathrm{M}, 20 \mathrm{~mL})$ was rapidly injected into that of $\mathrm{H}_{2} \mathrm{PtCl}_{6}(2.0 \mathrm{mM}, 20 \mathrm{~mL})$ containing PVP $178 \mathrm{mg}$ ); the latter solution was placed in a $\mathrm{MeOH}$ bath maintained at $0{ }^{\circ} \mathrm{C}$. The PVP-monomer-to-Pt molar ratio was 40:1. The resulting sample was purified (sample $\mathbf{a}^{\prime}$ ) and stored in the same manner as in the case of sample $\mathbf{a}$.

\subsubsection{Batch reduction with ethylene glycol (sample b)}

For reference, Pt:PVP was prepared by using a previously reported method [12] but with a slight modification. Ethylene glycol $(15 \mathrm{~mL})$ was dehydrated by heating at $140{ }^{\circ} \mathrm{C}$ for 30 min and cooled; subsequently, dried $\mathrm{H}_{2} \mathrm{PtCl}_{6}(0.3 \mathrm{mmol})$ and $\mathrm{NaOH}\left(180 \mathrm{mg} ; \mathrm{NaOH} / \mathrm{Pt}^{4+}=15\right)$ were added. The solution was stirred for $3 \mathrm{~h}$ at room temperature to ensure complete dissolution of $\mathrm{NaOH}$ and then heated in air at $140{ }^{\circ} \mathrm{C}$ for $\sim 2 \mathrm{~h}$ in a $50-\mathrm{mL}$ round bottom flask. After the solution was cooled to room temperature, PVP (1332 mg, PVP-monomer:Pt = 40:1) was added and the mixture was stirred overnight. Finally, Pt:PVP was purified by removing the inorganic ions and ethylene glycol (sample b) and stored, as done for sample a.

\subsubsection{Batch reduction with ethanol (sample c)}

Another reference Pt:PVP sample was prepared by following a literature method [11]. A mixture of aqueous solution of $\mathrm{H}_{2} \mathrm{PtCl}_{6}(10 \mathrm{mM}, 5 \mathrm{~mL})$ and ethanol/water solution $(9: 1, \mathrm{v} / \mathrm{v}, 45 \mathrm{~mL})$ of PVP (222 mg, PVP-monomer:Pt $=40: 1$ ) was refluxed at $90{ }^{\circ} \mathrm{C}$ in a $100-\mathrm{mL}$ round bottom flask for $3 \mathrm{~h}$ under air. Finally, Pt:PVP was purified by removing the inorganic ions and ethanol (sample c) and stored as per the method described for sample a.

\subsection{Characterization of Pt:PVP}

\subsubsection{UV-Visible spectroscopy}

UV-visible optical spectra of Pt:PVP dispersed in water were recorded by using a 
spectrophotometer (V-670, JASCO) under ambient condition.

\subsubsection{Transmission electron microscopy (TEM)}

The sizes of the PtNPs in Pt:PVP were determined by using a transmission electron microscope (JEM-2100F, JEOL) operated at $200 \mathrm{kV}$ with a magnification of 100,000-300,000. One drop of ethanol dispersion $(1 \mathrm{~mL})$ of Pt:PVP (Pt concentration: $\sim 0.3 \mathrm{mM}$ ) was cast on a carbon-coated copper grid placed on a filter paper. After complete drying, the grid was placed in the microscope for the measurements.

\subsubsection{X-ray diffractometry (XRD)}

X-ray diffraction (XRD) patterns of the PtNPs in Pt:PVP were measured by using a diffractometer (D8 ADVANCE, Bruker) with $\mathrm{Cu} \mathrm{K \alpha}$ radiation (1.5418 ̊̊) operated at $40 \mathrm{kV}$ and $40 \mathrm{~mA}$. The finely powdered sample ( $20 \mathrm{mg})$ was taken in a glass holder $(\phi=20 \mathrm{~mm})$, and the sample surface was flattened using a glass slide. The obtained diffraction patterns were simulated using the TOPAS-4 program.

\subsubsection{Inductively coupled plasma-atomic emission spectroscopy (ICP-AES)}

The Pt contents of the prepared Pt:PVP samples were determined by using an inductively coupled plasma atomic emission spectrometer (ICPE-9000, Shimadzu). Specimens were prepared by dissolving the solid Pt:PVP samples in concentrated aqua regia and diluting the solution with water, so that the Pt concentration was in the range 5-10 ppm. The amount of Pt leached during the catalytic reaction of Pt:PVP (sample a) (see 2.3.8) was also determined by ICP-AES analysis. Specimens were prepared by filtrating the Pt:PVP hydrosol after catalysis through a membrane filter having a cut-off molecular weight of $3 \mathrm{kDa}$ and washed twice with water $(10 \mathrm{~mL})$.

\subsubsection{X-ray photoelectron spectroscopy (XPS)}

X-ray photoelectron spectra of the Pt 4 f core level were recorded by using a spectrometer (JPS9010MC, JEOL) with $\mathrm{Mg} \mathrm{K \alpha}$ radiation (1253.6 eV); the spectrometer was operated at a base pressure of ca. $4 \times 10^{-7} \mathrm{~Pa}$. The samples were dried in a lyophilizer (FDU-2200, Eyela) for more than $24 \mathrm{~h}$, and 
then, a thin film of the sample was attached to a conductive carbon tape. Spectra were obtained at a takeoff angle of $45^{\circ}$ using a hemispherical energy analyzer with an energy resolution of $\sim 0.9 \mathrm{eV}$. The spectra were calibrated using the C 1s peaks of PVP as internal standards.

\subsubsection{X-ray absorbance spectroscopy (XAS)}

XAS experiments were conducted using the BL-7C beamline at Photon Factory of the Institute for Material Structure Science (PF-IMSS, KEK, Proposal No. 2008G638). Extended X-ray absorption fine structure (EXAFS) and X-ray absorption near-edge structure (XANES) spectra were recorded at the Pt $\mathrm{L}_{3}$ edge $(11564 \mathrm{eV})$. The synchrotron radiation emitted from the $2.5-\mathrm{GeV}$ storage ring was monochromatized using a $\mathrm{Si}(111)$ double-crystal monochromator calibrated by the $\mathrm{L}_{3}$ edge of metallic Pt. The powder samples were pressed into self-supporting disks and sealed into polyethylene bags. All the spectra were recorded at room temperature in the transmission mode using ion chambers for detection. EXAFS data were analyzed using a program REX2000 (Rigaku Co.). The EXAFS oscillations, $\chi(k)$, were obtained form the data by a spline smoothing and normalized by the edge height. The $k^{3}$-weighted $\chi(k)$ in the range of $35-145 \mathrm{~nm}^{-1}$ was Fourier transformed into $r$ space and the peak region $(0.230-0.313 \mathrm{~nm})$ was filtered and inversely Fourier transformed into $k$ space. The Fourierfiltered data were then analyzed by the curve fitting method; model parameters (back scattering amplitude and phase shift) were determined from an EXAFS oscillation observed for the bulk Pt.

\subsubsection{Fourier transform IR (FTIR) spectroscopy}

FTIR spectra of $\mathrm{CO}$ molecules in the presence of Pt:PVP were recorded using an FTIR spectrometer (FT/IR-4200, JASCO) operated at a resolution of $4 \mathrm{~cm}^{-1}$. Pt:PVP (0.6 mmol of Pt) particles were dispersed in $\mathrm{CH}_{2} \mathrm{Cl}_{2}(5 \mathrm{~mL})$ so that the $\mathrm{UV}$-visible spectra of the organosols had comparable areal intensities. The organosols were placed in a septum-sealed, two-neck flask, deaerated by freeze-pump-thaw cycles, and purged with $\mathrm{CO}$ at atmospheric pressure and $293 \pm 0.5 \mathrm{~K}$. Then, the

flask was connected to a $5-\mathrm{mL}$ airtight syringe via an IR cell $\left(\mathrm{CaF}_{2}\right.$ window, thickness: $\left.0.5 \mathrm{~mm}\right)$ by 1/16-in. Teflon tubes. Using the syringe, the organosols were transferred into the cell consecutively 
during purging, and FTIR spectra were recorded in the transmission mode by averaging over 20 scans.

After the spectral measurements, the solution was transferred back to the flask. Background spectra were recorded at the initial stages of the measurement using moisture-free, degassed $\mathrm{CH}_{2} \mathrm{Cl}_{2}$.

\subsubsection{General procedure for aerobic oxidation of $\mathrm{PhCH}_{2} \mathrm{OH}$}

Aerobic oxidation of $\mathrm{PhCH}_{2} \mathrm{OH}$ by Pt:PVP (sample a) was carried out using a temperaturecontrolled personal organic synthesizer (PPS-1510, Eyela) in an $\mathrm{O}_{2}$ atmosphere (pressure: 1 atm), in an aqueous solution without any base. The Pt:PVP $(2 \mathrm{mM}, 2 \mathrm{~mL})$ hydrosol was taken in a 10-mL test tube ( $\phi=15 \mathrm{~mm})$. The test tube was connected to a balloon filled with $\mathrm{O}_{2}(1 \mathrm{~atm})$ after the removal of air. Then, the temperature of the mixture was raised to $60{ }^{\circ} \mathrm{C}$ under vigorous stirring (1300 rpm), and $\mathrm{PhCH}_{2} \mathrm{OH}(20.7 \mu \mathrm{L}, 0.2 \mathrm{mmol})$ was directly added on top of this hydrosol by a microsyringe with a long needle. Under these conditions, the Pt content was 2 mol\% with respect to the substrate. The products were extracted four times with AcOEt $(\sim 15 \mathrm{~mL})$ and dried over $\mathrm{Na}_{2} \mathrm{SO}_{4}$. The AcOEt solution was then diluted to $100 \mathrm{~mL}$ and used for the gas chromatographic (GC-2014, Shimadzu) estimation of the chemical identity and absolute yield of the products by the external standard method. Average values and the standard deviations of the yields were determined by three independent experiments.

Reusability of Pt:PVP (sample a) as catalysts was studied as follows. After the first catalytic run, EtOAc remained on the Pt:PVP hydrosols was removed completely by passing dry air for 30 min. One drop $(\sim 10 \mu \mathrm{L})$ of the hydrosol was sampled for TEM analysis and the total volume of the hydrosol was adjusted to $2 \mathrm{~mL}$ by adding water. The test tube was connected to a balloon filled with $\mathrm{O}_{2}(1$ atm) and $\mathrm{PhCH}_{2} \mathrm{OH}(20.7 \mu \mathrm{L})$ was added to the hydrosol $\left(60{ }^{\circ} \mathrm{C}\right)$ under vigorous stirring $(1300 \mathrm{rpm})$. Yields of the products after $5 \mathrm{~h}$ were determined by GC analysis. The above procedure was repeated 4 times. Average values and the standard deviations of the yields were determined by three independent experiments.

\section{Results and Discussion}

\subsection{Efficiency of the microfluidic reduction}


ICP measurements indicated that the Pt contents of samples $\mathbf{a}, \mathbf{b}$, and $\mathbf{c}$ were $4.5,4.1$ and 4.4 wt\%, respectively. Fig. 1A shows the optical absorption spectra of the hydrosols of samples a-c after normalization with the Pt concentration. All the spectra exhibited exponential-like profiles due to intraand interband optical transitions, as in the case of the PtNPs reported so far $[10,11,13,17,20]$. The spectral area for sample a was nearly the same as those for samples $\mathbf{b}$ and $\mathbf{c}$, suggesting that the $\mathrm{Pt}^{4+}$ ions were completely reduced by $\mathrm{BH}_{4}^{-}$when the micromixer was used. To further confirm the role of the micromixer in the efficient production of PtNPs, we compared the optical spectra of samples a and $\mathbf{a}^{\prime}$ (see Fig. 1A). The spectral intensity for sample $\mathbf{a}^{\prime}$ was $\sim 60 \%$ of that for sample a. In addition, $\mathrm{Pt}^{2+}$ ions were detected in the filtrates of sample $\mathbf{a}^{\prime}$, but not in the filtrate of sample a (Fig. 1B). These results clearly indicated that the $\mathrm{Pt}^{4+}$ ions could be reduced completely by mixing with $\mathrm{BH}_{4}^{-}$in the micromixer. Our findings support the previous proposal by Glaunsinger [14], who suggested that the reduction of $\mathrm{Pt}^{4+}$ is prevented by the rapid hydrolysis of $\mathrm{NaBH}_{4}$ by the PtNPs produced in the initial stages of the reaction (Scheme 1). To confirm this explanation, we compared the yields of the PtNPs produced by batch mixing with and without Pt:PVP [23]. The intensity of the optical spectrum of the Pt:PVP produced in the presence of Pt:PVP was $35 \%$ lower than in the case of the PtNPs produced without PtNPs (data not shown). 

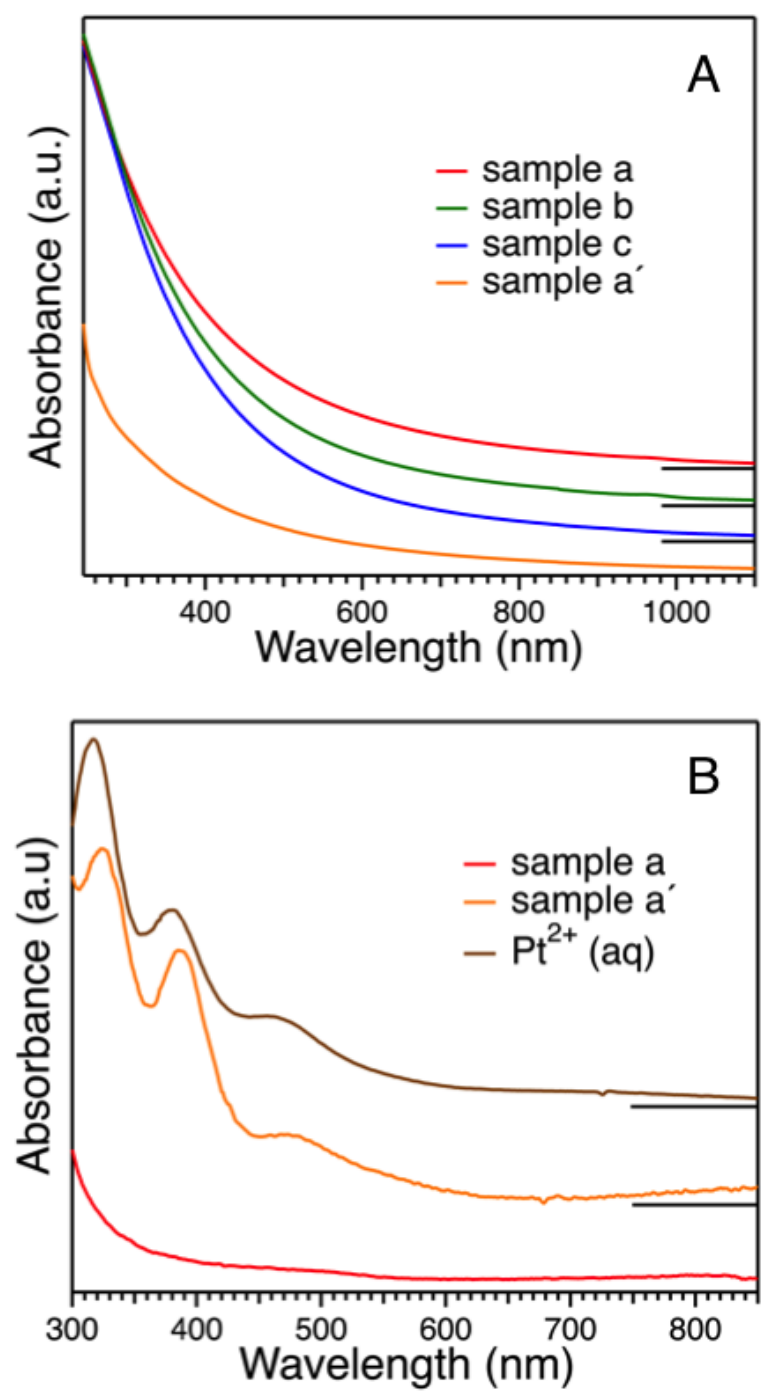

Fig. 1. (A) UV-visible spectra of Pt:PVP (samples a-c and $\mathbf{a}^{\prime}$ ). (B) UV-visible spectra of the filtrates collected by the ultrafiltration of the hydrosol of sample a and a'. Optical spectrum of the aqueous solution of $\mathrm{K}_{2} \mathrm{PtCl}_{4}$ is shown for comparison.

\subsection{Size distributions}

Representative TEM images of samples $\mathbf{a}-\mathbf{c}$ are shown in Fig. 2. Samples $\mathbf{a}$ and $\mathbf{b}$ were found to comprise spherical particles, whereas sample c contained nonspherical particles. The diameters of more than 300 PtNPs were measured from the TEM images and histograms showing the nanoparticle population as a function of the particle diameter were plotted (Fig. 2). The average diameters of the $\operatorname{PtNPs}\left(d_{\mathrm{TEM}}\right)$ for samples $\mathbf{a}, \mathbf{b}$, and $\mathbf{c}$ were found to be $1.4 \pm 0.3,1.8 \pm 0.4$ and $3.2 \pm 0.7 \mathrm{~nm}$, respectively. The powder XRD patterns for samples a-c indicated the formation of fcc crystallites (Fig. 3). The 
average diameters of the Pt crystallites $\left(d_{\mathrm{XRD}}\right)$ were evaluated by applying the Scherrer formula to the $\operatorname{Pt}(111)$ diffraction peaks. The crystallite sizes determined by XRD analysis were comparable to the average diameters determined from the TEM analysis (Table 1). To the best of my knowledge, sample a synthesized using the micromixer had the smallest particle size among Pt:PVP particles reported so far $[3,6,10,11,13,16]$.
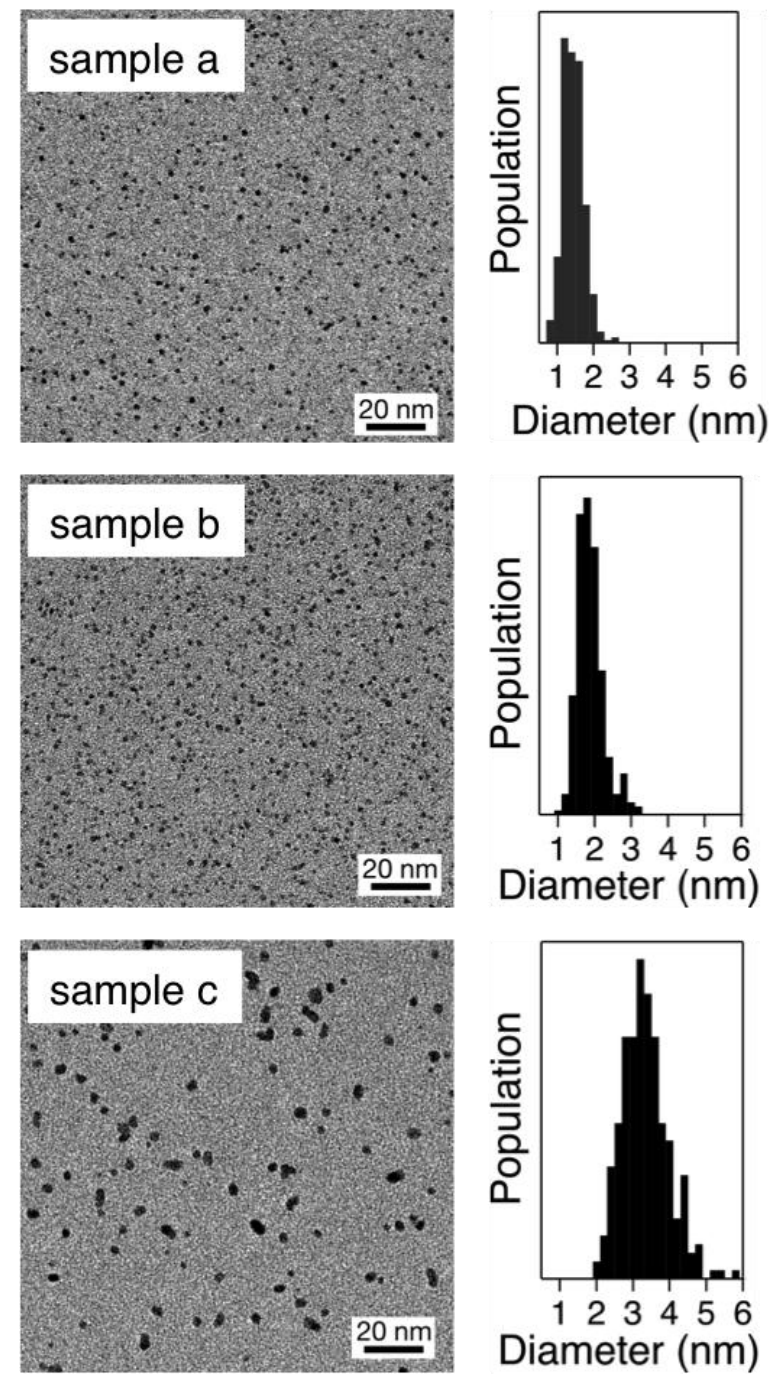

Fig. 2. Representative TEM images and core size distributions of Pt:PVP (samples a-c). 


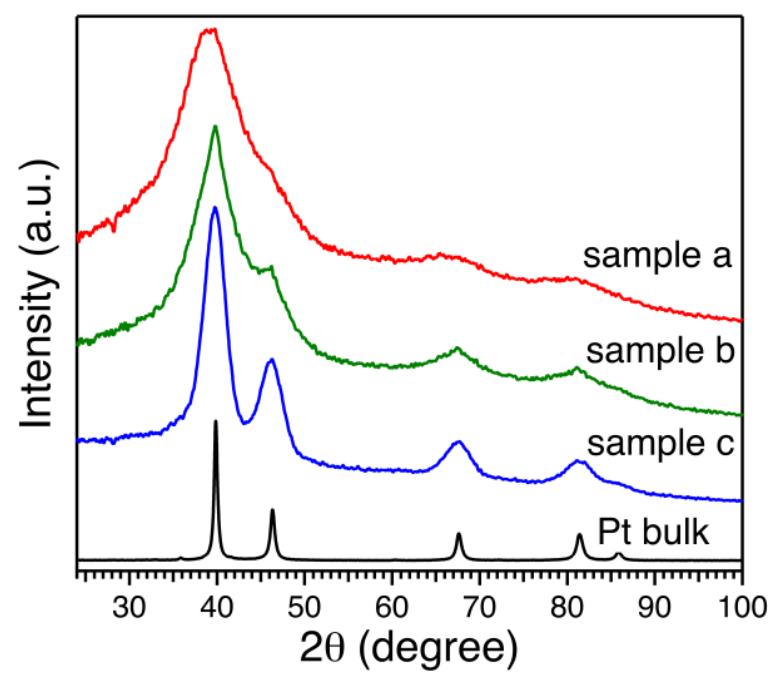

Fig. 3. XRD patterns of Pt:PVP (samples a-c) and bulk Pt.

\subsection{Geometric and electronic structures}

Fig. 4 shows the X-ray photoelectron spectra of the Pt 4 f region of sample a. Two peaks due to Pt $4 \mathrm{f}_{7 / 2}$ and $\mathrm{Pt} 4 \mathrm{f}_{5 / 2}$ were observed at binding energies of 70.2 and $73.4 \mathrm{eV}$, respectively (Table 1 ). No peak attributable to unreduced Pt ions was seen; this result was consistent with the results of the optical measurements described in Section 3.1. Notably, the peak positions for sample a were shifted to the lower-energy side as compared to those for bulk Pt, suggesting that the PtNPs in sample a are negatively charged because of the electron-donating nature of PVP. A similar behavior has been reported for Pt:PVP [28] and Au:PVP [24].

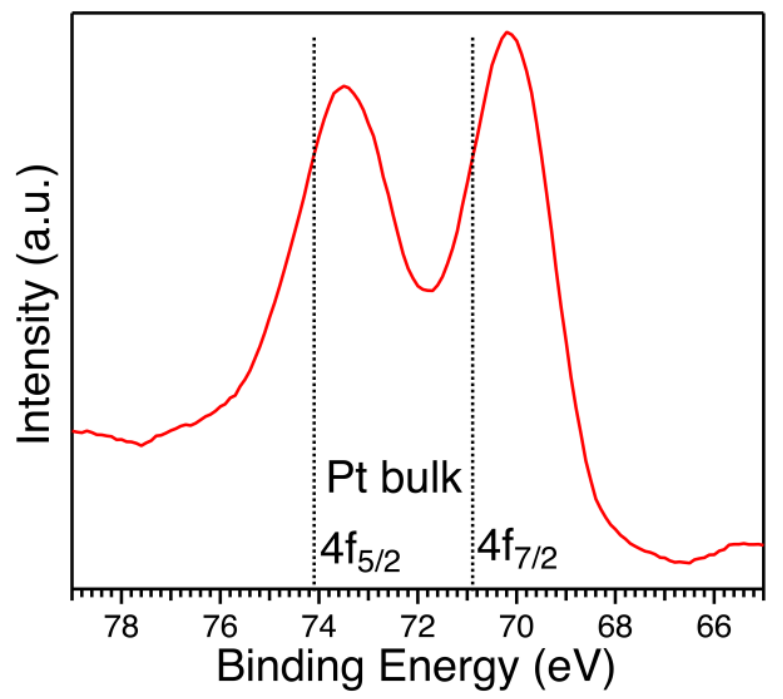

Fig. 4. X-ray photoelectron spectrum of Pt:PVP (sample a). The dotted lines represent the electron binding energies for bulk Pt. 


\section{Table 1}

Structural characterizations of Pt:PVP.

\begin{tabular}{ccccc}
\hline samples & $d_{\text {TEM }}(\mathrm{nm})$ & $d_{\text {XRD }}(\mathrm{nm})$ & $a(\AA)^{\mathrm{a}}$ & $\mathrm{BE}\left(\mathrm{Pt} 4 \mathrm{f}_{7 / 2}\right) / \mathrm{BE}\left(\mathrm{Pt} 4 \mathrm{f}_{5 / 2}\right)(\mathrm{eV})$ \\
\hline $\mathbf{a}$ & $1.4 \pm 0.3$ & 1.2 & 3.99 & $70.2 / 73.4$ \\
$\mathbf{b}$ & $1.8 \pm 0.4$ & 1.6 & 3.92 & - \\
$\mathbf{c}$ & $3.2 \pm 0.7$ & 3.2 & 3.92 & - \\
Bulk Pt & - & - & 3.92 & $70.9 / 74.1$ \\
\hline
\end{tabular}

alattice constant.

The valence states of samples a and $\mathbf{c}$ were characterized by XAS at the Pt $\mathrm{L}_{3}$ edge. Fig. 5 shows the normalized XANES spectra of these samples. The absorption peak at $11564 \mathrm{eV}$, called white line, is associated with the electronic excitation from $2 p_{3 / 2}$ to $5 d_{5 / 2}$ above the Fermi level [25]. The intensity of the white line for sample $\mathbf{a}$ is much higher than those in the case of sample $\mathbf{c}$ and bulk Pt. This indicates an increase in the d-band vacancy for sample a, which has the smallest particle diameter, as stated in previous report [26].

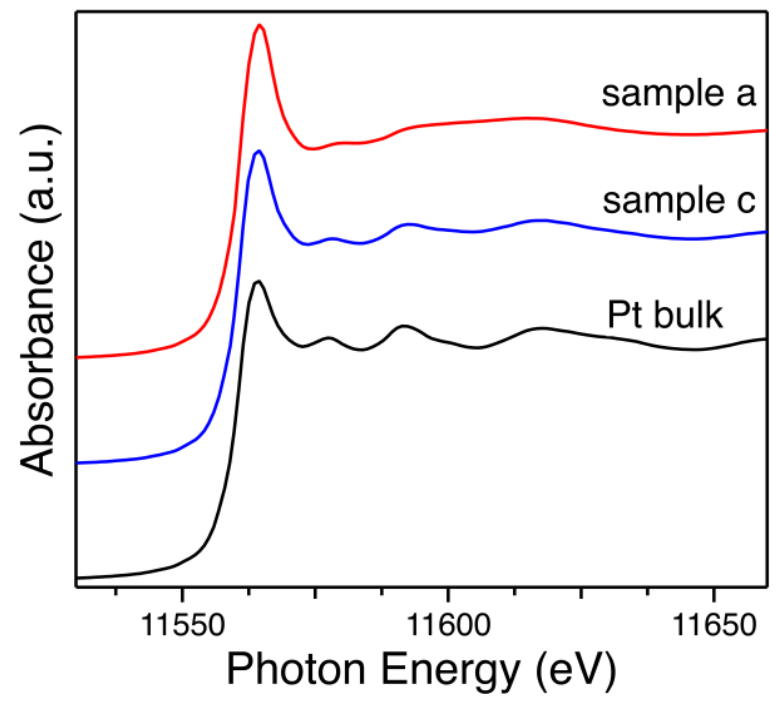

Fig. 5. XANES spectra of Pt:PVP (samples a and c) and bulk Pt.

The $k^{3}$-weighted Fourier transformed EXAFS spectra of samples a and $\mathbf{c}$ and bulk Pt are shown in Fig. 6(A). The sharp peak for sample $\mathbf{c}$ in the range of $0.230-0.313 \mathrm{~nm}$ is assigned to the Pt-Pt shell. Although the corresponding peak for sample a is much weaker, the spectrum was Fourier-filtered (solid line of Fig. 6(B)) over the same region and analyzed by a curve-fitting technique (dotted line of Fig. 6(B)). Table 2 summarizes the structure parameters of samples a and c thus obtained. The Pt-Pt 
coordination number $(C N)$ for sample a is smaller than that for sample $\mathbf{c}$, which is associated with higher population of low-coordination sites in smaller NPs [10] and is consistent with the results of TEM and XRD measurements (Figs. 2 and 3, Table 1).
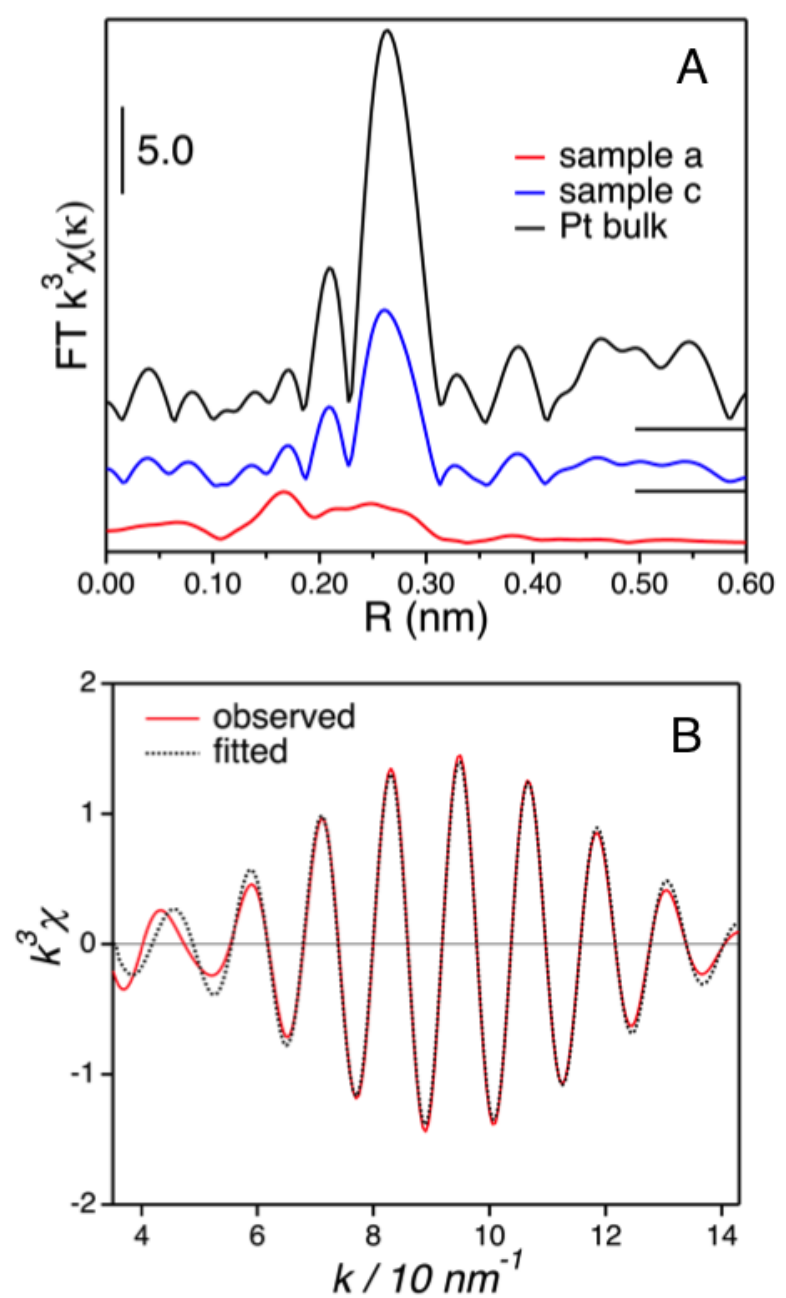

Fig. 6. (A) Fourier transformed EXAFS spectra of Pt:PVP (samples a and c) and bulk Pt. (B) Fourierfiltered EXAFS spectrum and best-fit curve of Pt:PVP (sample a).

Table 2

Results of EXAFS analysis of Pt:PVP

\begin{tabular}{cccccc}
\hline samples & shell & $C N^{\mathrm{a}}$ & $R(\mathrm{~nm})^{\mathrm{b}}$ & $\Delta E(\mathrm{eV})^{\mathrm{c}}$ & $\sigma(\mathrm{nm})^{\mathrm{d}}$ \\
\hline $\mathbf{a}$ & $\mathrm{Pt}-\mathrm{Pt}$ & $5.3 \pm 1.6$ & $0.273 \pm 0.002$ & $-0.3 \pm 3.9$ & $0.0103 \pm 0.0017$ \\
$\mathbf{c}$ & $\mathrm{Pt}-\mathrm{Pt}$ & $7.3 \pm 0.6$ & $0.276 \pm 0.001$ & $-1.1 \pm 1.1$ & $0.0070 \pm 0.0006$ \\
Bulk Pt & $\mathrm{Pt}-\mathrm{Pt}$ & 12 & 0.277 & 0.0 & 0.006 \\
\hline
\end{tabular}

a coordination number. ${ }^{b}$ coordination distance. ${ }^{c}$ The difference between theoretical and experimental threshold energies. ${ }^{\mathrm{d}}$ Debye-Waller factor.

Fig. 7A compares the FTIR spectra of $\mathrm{CO}$ for samples a-c with a normalized PVP/Pt ratio 
(40:1); the spectra were recorded after purging the dispersion with CO for $20 \mathrm{~min}$. The spectrum of sample a showed five peaks at 1850, 1994, 2021, 2058, and $2137 \mathrm{~cm}^{-1}$. The peak at $2137 \mathrm{~cm}^{-1}$ was assigned to the free $\mathrm{CO}$ dissolved in $\mathrm{CH}_{2} \mathrm{Cl}_{2}[24,27]$. The peak at $2058 \mathrm{~cm}^{-1}$ was the strongest among the aforementioned five peaks and was assigned to CO adsorbed on a single Pt atom on the terrace [27], whereas the weak peak at $1850 \mathrm{~cm}^{-1}$ was due to a bridge site between two $\mathrm{Pt}$ atoms on the terrace. The peak position for terrace $\mathrm{CO}$ showed a blue shift with an increase in the particle size, suggesting limited back-donation of electrons from the large PtNPs to CO. This could be because the electronic charge density for larger PtNPs is lower than that of smaller PtNPs, as observed in a previous XPS analysis [28]. Interestingly, two peaks at 1994 and $2021 \mathrm{~cm}^{-1}$, which had not been reported previously, were observed in the present study. The peak intensity relative to that for the terrace $\mathrm{CO}$ increased rapidly with a decrease in the size of the PtNPs. These two new peaks were assigned to $\mathrm{CO}$ attached to lowcoordination sites such as edges and vertices, since it could be reasonably assumed that smaller NPs have a greater number of edge and vertex atoms than do larger NPs.

Fig. 7B shows the time evolution of the FTIR spectra of CO for sample a, recorded when purging the dispersion with CO. The intensities of the peaks at 1994,2021 , and $2058 \mathrm{~cm}^{-1}$ increased with time, whereas the peak positions remained unchanged. The peaks due to the edges and vertices grew more slowly than did those due to the terrace sites. This indicated that the $\mathrm{CO}$ molecules preferentially adsorb on the terrace sites in the low-coverage regime and then on the edges and vertices in the high-coverage regime. 

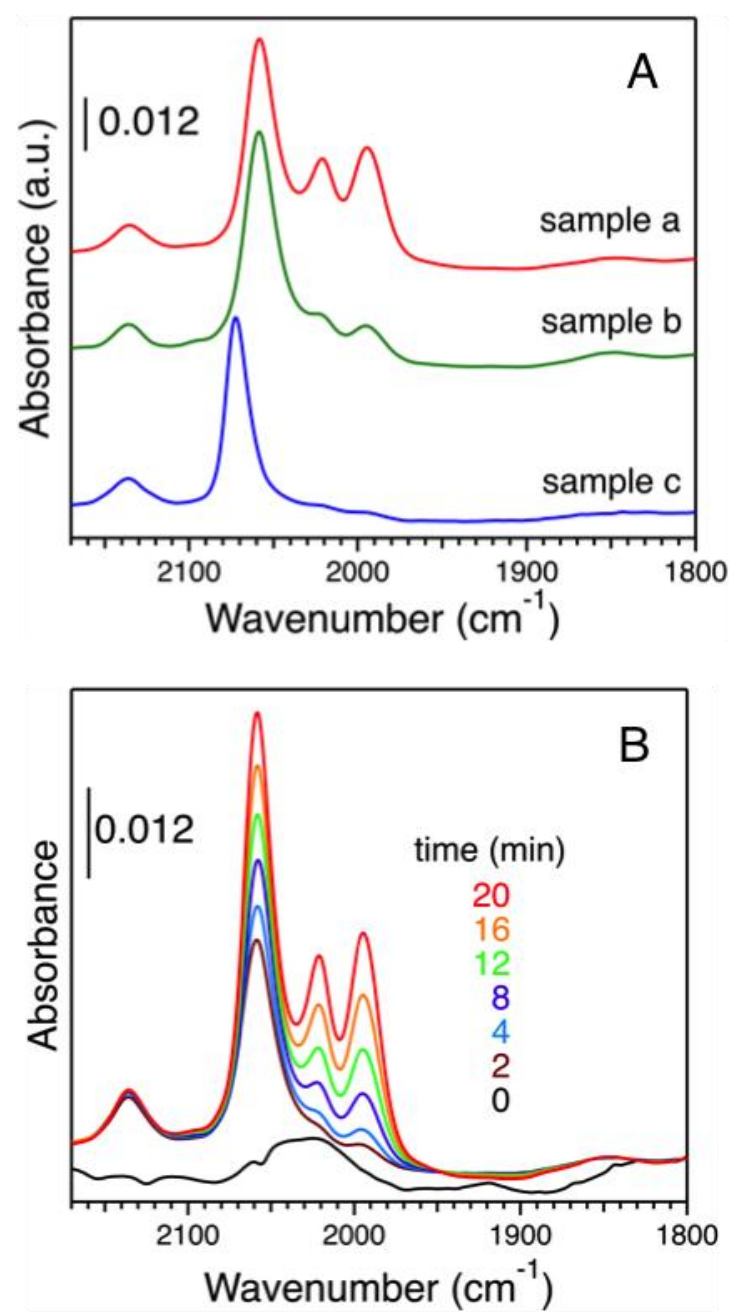

Fig. 7. (A) FTIR spectra of CO adsorbed on Pt:PVP (sample a-c). (B) Time evolution of FTIR spectra of CO adsorbed on Pt:PVP (sample a).

\subsection{Oxidation of $\mathrm{PhCH}_{2} \mathrm{OH}$}

Pt:PVP particles (sample a) dispersed in water catalyzed the aerobic oxidation of $\mathrm{PhCH}_{2} \mathrm{OH}$ even in the absence of base. Fig. 8 shows the time course of the conversion of $\mathrm{PhCH}_{2} \mathrm{OH}$ in the presence of sample a at $60{ }^{\circ} \mathrm{C}$. Interestingly, this reaction afforded $\mathrm{PhCHO}$ as the major product, in sharp contrast to the selective production of $\mathrm{PhCO}_{2} \mathrm{H}$ catalyzed by the PtNPs reported previously $[2,3,5,6]$. The yield of $\mathrm{PhCHO}$ became as high as $84 \%$ after $4 \mathrm{~h}$. The high selectivity of sample a to the aldehyde product can be ascribed to several factors, such as size, geometric and electronic structures of the PtNPs, which would be investigated in a future study. 


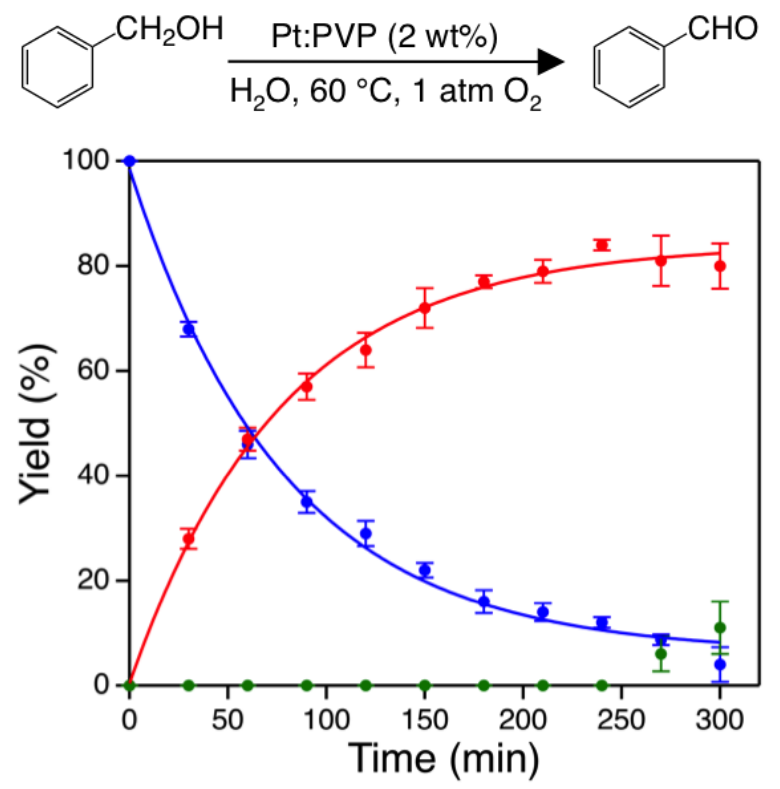

Fig. 8. Time course of conversion of $\mathrm{PhCH}_{2} \mathrm{OH}$ to $\mathrm{PhCHO}$ and $\mathrm{PhCO}_{2} \mathrm{H}$ catalyzed by sample a in water. Reaction conditions: catalyst (sample a) amount, $17.4 \mathrm{mg}(0.004 \mathrm{mmol}$ of $\mathrm{Pt}) ; \mathrm{PhCH}_{2} \mathrm{OH}, 21 \mu \mathrm{L}$ (substrate-to-platinum molar ratio $=50: 1$ ); volume of water, $2 \mathrm{~mL}$; temperature, $333 \mathrm{~K} ; \mathrm{O}_{2}, 1$ atm; stirring speed, $1300 \mathrm{rpm}$. The error bars represent the standard deviations of the yields determined by three independent measurements. The curves are fitted with exponential curves, assuming that the reaction is first-order with respect to the substrate.

Fig. 9A shows the average diameters of the PtNPs after catalytic usage of sample a. The average diameters of PtNPs after catalytic usage are comparable to the initial one $(1.4 \pm 0.3 \mathrm{~nm})$. In addition, the yields of $\mathrm{PhCHO}$ after $5 \mathrm{~h}$ do not change appreciably (Fig. 9B). These results indicate that Pt:PVP (sample a) can be reused as oxidation catalysts under the present conditions at least four times without any loss in the activity. However, we found that $0.6 \%$ of Pt is leached out from Pt:PVP into the water phase after the reaction for $5 \mathrm{~h}$. In order to estimate the contribution of these leached Pt species to the oxidation reaction, the conversion of $\mathrm{PhCH}_{2} \mathrm{OH}$ by the leached $\mathrm{Pt}$ was measured. It was found that the conversion was less than $1 \%$ even when the amount of leached Pt is increased 10 times. This result indicates that oxidation of $\mathrm{PhCH}_{2} \mathrm{OH}$ is not catalyzed by leached Pt species, but exclusively by Pt:PVP ( sample a ). 

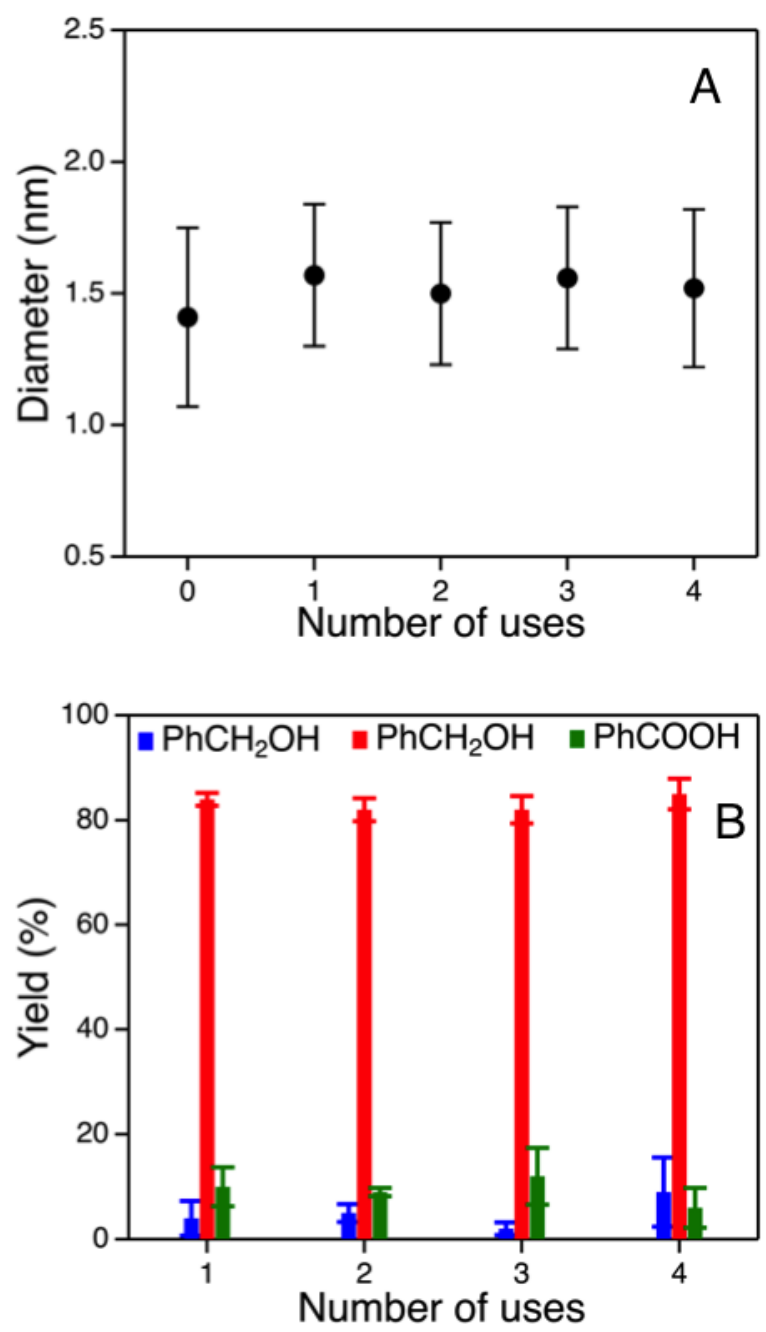

Fig. 9. (A) Diameter of PtNPs in Pt:PVP (sample a). The diameter of the as-prepared Pt:PVP is plotted at zero position. (B) Yield of $\mathrm{PhCH}_{2} \mathrm{OH}, \mathrm{PhCHO}$, and $\mathrm{PhCO}_{2} \mathrm{H}$ after 5 h. Reaction conditions: catalyst (sample a) amount, $17.4 \mathrm{mg}(0.004 \mathrm{mmol}$ of $\mathrm{Pt}) ; \mathrm{PhCH}_{2} \mathrm{OH}, 21 \mu \mathrm{L}$ (substrate-to-platinum molar ratio = 50:1); volume of water, $2 \mathrm{~mL}$; temperature, $333 \mathrm{~K} ; \mathrm{O}_{2}, 1 \mathrm{~atm}$; stirring speed, $1300 \mathrm{rpm}$. The error bars represent the standard deviations of the yields determined by three independent measurements.

\section{Summary}

We demonstrated that the yield of PtNPs produced by micromixing was greatly enhanced because of the compete reduction of $\mathrm{Pt}^{4+}$ ions by $\mathrm{BH}_{4}^{-}$. The low yield of the PtNPs produced in the absence of micromixing was ascribed to the hydrolytic decomposition of $\mathrm{BH}_{4}{ }^{-}$by the PtNPs produced in the initial stages of the reaction. In addition, the diameter of the PtNPs produced by micromixing could be reduced to $1.4 \pm 0.3 \mathrm{~nm}$ under optimized conditions. The synthesized Pt:PVP was negatively 
charged and had a high population of edges and vertices on the surface. Our Pt:PVP selectively oxidized

$\mathrm{PhCH}_{2} \mathrm{OH}$ to $\mathrm{PhCHO}$ at $60{ }^{\circ} \mathrm{C}$ even when no base was added to the aqueous solution.

\section{Acknowledgment}

This research was financially supported by funding program for next generation world-leading researchers (NEXT Program) (GR-003). Prof. Masatoshi Osawa of Hokkaido University is acknowledged for his fruitful discussion on the FTIR analysis.

\section{References}

[1] R. A. Sheldon, Chem. Commun. (2008) 3352-3365.

[2] Y. M. A. Yamada, T. Arakawa, H. Hocke, Y. Uozumi, Angew. Chem. Int. Ed. 46 (2007) 704-706.

[3] T. Wang, C.-X. Xiao, L. Yan, L. Xu, J. Luo, H. Shou, Y. Kou, H. Liu, Chem. Commun. (2007) 4375-4377.

[4] Y. H. Ng, S. Ikeda, T. Harada, Y. Morita, M. Matsumura, Chem. Commun. (2008) 3181-3183.

[5] P. Maity, C. S. Gopinath, S. Bhaduri, G. K. Lahiri, Green Chem. 11 (2009) 554-561.

[6] T. Wang, H. Shou, Y. Kou, H. Liu, Green Chem. 11 (2009) 562-568.

[7] R. A. Sheldon, J. Chem. Tech. Biotechnol. 68 (1997) 381-388.

[8] P. T. Anastas, J. C. Warner, Green Chemistry, Theory and Practice; Oxford University Press: Oxford, U.K., 1998.

[9] T. S. Ahmadi, Z. L. Wang, T. C. Green, A. Henglein, M. A. El-Sayed, Science 272 (1996) 19241926.

[10] N. Toshima, M. Harada, T. Yonezawa, K. Kushihashi, K. Asakura, J. Phys. Chem. 95 (1991) $7448-7453$.

[11] T. Teranishi, M. Hosoe, T. Tanaka, M. Miyake, J. Phys. Chem. B 103 (1999) 3818-3827.

[12] Y. Wang, J. Ren, K. Deng, L. Gui, Y. Tang, Chem. Mater. 12 (2000) 1622-1627.

[13] R. M. Rioux, H. Song, J. D. Hoefelmeyer, P. Yang, G. A. Somorjai, J. Phys. Chem. B 109 (2005) 2192-2202.

[14] P. R. V. Rheenen, M. J. McKelvy, W. S. Glaunsinger, J. Solid State Chem. 67 (1987) 151-169.

[15] K. Niesz, M. Grass, G. A. Somorjai, Nano Lett. 5 (2005) 2238-2240.

[16] H. Lee, S. E. Habas, S. Kweskin, D. Butcher, G. A. Somorjai, P. Yang, Angew. Chem. Int. Ed. 45 (2006) 7824-7828.

[17] M. R. Knecht, M. G. Weir, V. S. Myers, W. D. Pyrz, H. Ye, V. Petkov, D. J. Buttrey, A. I. Frenkel, R. M. Crooks, Chem. Mater. 20 (2008) 5218-5228. 
[18] Y. Borodko, C. M. Thompson, W. Huang, H. B. Yildiz, H. Frei, G. A. Somorjai, J. Phys. Chem. C 115 (2011) 4757-4767.

[19] L. Qiu, F. Liu, L. Zhao, W. Yang, J. Yao, Langmuir 22 (2006) 4480-4482.

[20] T. Herricks, J. Chen, Y. Xia, Nano Lett. 4 (2004) 2367-2371.

[21] (a) H. C. Brown, C. A. Brown, J. Am. Chem. Soc. 84 (1962) 1493-94. (b) H. C. Brown, C. A. Brown, J. Am. Chem. Soc. 84 (1962) 1494-95.

[22] H. Tsunoyama, N. Ichikuni, T. Tsukuda, Langmuir 24 (2008) 11327-11330.

[23] To check the reduction of $\mathrm{Pt}^{4+}$ ions by $\mathrm{NaBH}_{4}$ in the presence of Pt:PVP, we intentionally added $0.1 \mathrm{mM}$ Pt:PVP to a $1.0 \mathrm{mM} \mathrm{Pt}{ }^{4+}$ solution. Reduction and other processes were similar to those observed for sample $\mathbf{a}^{\prime}$.

[24] H. Tsunoyama, N. Ichikuni, H. Sakurai, T. Tsukuda, J. Am. Chem. Soc. 131 (2009) 7086-7093.

[25] Y. Iwasawa (Editor), X-ray Absorption Fine Structure for Catalysts and Surfaces, World Scientific Publishing Co., Singapore, 1996.

[26] E. Bus, J. A. van Bokhoven, J. Phys. Chem. C 111 (2007) 9761-9768.

[27] D. de Caro, J. S. Bradley, New J. Chem. 22 (1998) 1267-1273.

[28] P. Gruene, A. Fielicke, G. Meijer, D. M. Rayner, Phys. Chem. Chem. Phys. 10 (2008) 6144-6149. 